University of Wollongong

Research Online

Australian Institute for Innovative Materials -

Papers

Australian Institute for Innovative Materials

$1-1-2014$

TiO2 coated three-dimensional hierarchically ordered porous sulfur electrode for the lithium/sulfur rechargeable batteries

Hongqiang Wang

University of Wollongong, hw571@uowmail.edu.au

Sha Li

University of Wollongong, sl739@uowmail.edu.au

Dan Li

University of Wollongong, danli@uow.edu.au

Zhixin Chen

University of Wollongong, zchen@uow.edu.au

Hua-Kun Liu

University of Wollongong, hua@uow.edu.au

See next page for additional authors

Follow this and additional works at: https://ro.uow.edu.au/aiimpapers

Part of the Engineering Commons, and the Physical Sciences and Mathematics Commons

Research Online is the open access institutional repository for the University of Wollongong. For further information contact the UOW Library: research-pubs@uow.edu.au 


\title{
TiO2 coated three-dimensional hierarchically ordered porous sulfur electrode for the lithium/sulfur rechargeable batteries
}

\begin{abstract}
A three-dimensional (3D) hierarchically ordered mesoporous carbon-sulfur composite slice coated with a thin TiO2 layer has been synthesized by a low-cost process and investigated as a cathode for the lithiumsulfur batteries. The $\mathrm{TiO} 2$ coated carbon sulfur composite thin slice works as a binder-free cathode without any current collectors for lithium-sulfur batteries. The hierarchical architecture provides a 3D conductive network for electron transfer, open channels for ion diffusion and strong confinement of soluble polysulfides. Meanwhile, TiO2 (titanium dioxide) coating layer could further effectively prevent the dissolution of polysulfides and also improve the strength of the entire electrode, thereby enhancing the electrochemical performance. As a result, after TiO2 coating, the electrode demonstrates excellent cycling performance, with a discharge capacity of $608 \mathrm{mAh} / \mathrm{g}$ at $0.2 \mathrm{C}$ current rate and $500 \mathrm{mAh} / \mathrm{g}$ at $1 \mathrm{C}$ current rate after 120 cycles, respectively.
\end{abstract}

\section{Keywords}

coated, three, dimensional, hierarchically, ordered, porous, sulfur, electrode, rechargeable, lithium, batteries, tio2

Disciplines

Engineering | Physical Sciences and Mathematics

\section{Publication Details}

Wang, H., Li, S., Li, D., Chen, Z., Liu, H. Kun. \& Guo, Z. (2014). TiO2 coated three-dimensional hierarchically ordered porous sulfur electrode for the lithium/sulfur rechargeable batteries. Energy, 75 597-602.

\section{Authors}

Hongqiang Wang, Sha Li, Dan Li, Zhixin Chen, Hua-Kun Liu, and Zaiping Guo 


\title{
$\mathrm{TiO}_{2}$ coated three-dimensional hierarchically ordered porous sulfur electrode for the lithium/sulfur rechargeable batteries
}

\author{
Hongqiang Wang ${ }^{\mathrm{a}}$, Sha $\mathrm{Li}^{\mathrm{a}}$, Dan $\mathrm{Li}^{\mathrm{a}}$, Zhixin Chen ${ }^{\mathrm{c}}$, Hua Kun Liu ${ }^{\mathrm{a}}$, Zaiping Guo, a,c,*
${ }^{\text {a }}$ Institute for Superconducting \& Electronic Materials, University of Wollongong, NSW 2522, Australia Email: zguo@uow.edu.au
${ }^{\mathrm{b}}$ Hubei Collaborative Innovation Center for Advanced Organic Chemical Materials, College of Chemistry and Chemical Engineering, Hubei University, Wuhan 430062, P.R. China

${ }^{c}$ School of Mechanical, Materials \& Mechatronics Engineering, University of Wollongong, NSW 2500, Australia.

ABSTRACT: A three-dimensional (3D) hierarchically ordered mesoporous carbon-sulfur composite slice coated with a thin $\mathrm{TiO}_{2}$ layer has been synthesized by a low-cost process and investigated as a cathode for the lithium-sulfur batteries. The $\mathrm{TiO}_{2}$ coated carbon sulfur composite thin slice works as a binder-free cathode without any current collectors for lithium-sulfur batteries. The hierarchical architecture provides a 3D conductive network for electron transfer, open channels for ion diffusion and strong confinement of soluble polysulfides. Meanwhile, $\mathrm{TiO}_{2}$ coating layer could further effectively prevent the dissolution of polysulfides and also improve the strength of the entire electrode, thereby enhancing the electrochemical performance. As a result, after $\mathrm{TiO}_{2}$ coating, the electrode demonstrates excellent cycling performance, with a discharge capacity of $608 \mathrm{mAh} / \mathrm{g}$ at $0.2 \mathrm{C}$ current rate and $500 \mathrm{mAh} / \mathrm{g}$ at $1 \mathrm{C}$ current rate after 120 cycles, respectively.

Keywords: 3D architecture, binder-free, ordered mesoporous structure, mass production

\section{Introduction}

Rechargeable lithium ion batteries (LIBs) have achieved great development during the past decades as power sources for various portable devices such as laptops, smart phones and electric vehicles [1-4]. However, the specific energy of the commercialized lithium ion batteries will become insufficient for the future electric vehicles due to the low capacity of conventional electrode materials. Therefore, new electrode materials with higher gravimetric and volumetric capacity should be developed. Sulfur, as one of the most abundant elements on the earth, can offer ultra-high energy density (theoretically $2567 \mathrm{Wh} \mathrm{kg}^{-1}$ ) and high theoretical specific capacity $\left(1675 \mathrm{mAh} \cdot \mathrm{g}^{-1}\right)$, making it a very promising cathode candidate for the next generation batteries [5-8]. The Li-S battery system may suffer, however, from 
several disadvantages, including the low conductivity of sulfur and lithium sulfide [9] as well as the large volume changes of sulfur particles during charge and discharge processes. A more significant challenge that needs to be overcome is the high solubility of the intermediate lithium polysulfides in organic electrolytes. The soluble polysulfides can diffuse from the cathode and react with the lithium anode to generate insoluble lower-order polysulfides in the form of $\mathrm{Li}_{2} \mathrm{~S}$ or $\mathrm{Li}_{2} \mathrm{~S}_{2}$, resulting in the precipitation of these species on the surface during cyclic processes $[10,11]$. These issues lead to the low utilization of sulfur, which is the active material, low coulombic efficiency of the sulfur cathode, and fast capacity fading [12-15].

There are two basic strategies to address this problem in terms of designing nanostructured sulfur cathodes. One is to constrain the sulfur or lithium polysulfide within a framework by using host materials, such as various types of porous carbon $[16,17]$, hollow carbon spheres $[13,18]$, carbon nanotubes $[19,20]$, graphene [21,22], graphene oxide [23,24], and conductive polymers [25,26]. An alternative route is to build a physical barrier to prevent soluble polysulfides from dissolving in the organic electrolyte by forming a thin film to acts as a coating on the surface of the active material. Such barrier materials include polymers $[27,28]$ and metal oxides such as $\mathrm{TiO}_{2}$ [29], $\mathrm{Al}_{2} \mathrm{O}_{3}$ [30], $\mathrm{SiO}_{\mathrm{x}}$, and $\mathrm{VO}_{\mathrm{x}}$ [31]. Compared with a polymer coating, a metal oxide coating layer could almost completely block out-diffusion of the polysulfides and enhance the strength of the entire electrode to withstand structural damage during long cycle testing.

Herein, we employ 3D hierarchical porous carbon slice (C) as an improved confined matrix for high-level sulfur impregnation. 3D porous nanostructured carbon is highly desirable for high-performance electrode materials, as it can not only provide a continuous electron pathway to ensure good electrical contact, but also facilitates the transport of ions and electrolyte. Additionally, the well-developed 3D structure with macropores and ordered interconnected mesopores can encapsulate a large amount of sulfur, provide a large specific surface area, and facilitate fast ion transport, thus enhancing the electrochemical performance of electrodes. In order to trap the dissolved polysulfides more effectively, a $\mathrm{TiO}_{2}$ layer was further coated on the surface of the as-prepared porous carbon-sulfur composite to obtain carbon-sulfur- $\mathrm{TiO}_{2}$ composite (Fig.1). The as-prepared $\mathrm{TiO}_{2}$ coated carbon-sulfur composite slice could be used as cathode directly without further electrode preparation process, therefore, no inert weight, i.e. binders and metal substrate, is included in the electrodes.

\section{Experimental}

\subsection{Synthesis of hierarchical porous-structured carbon}


The ordered mesoporous carbon-silica composite slice with macroporous architecture were synthesized through an evaporation-induced coating and self-assembly method using foam as template, as described by Zhao et al [32]. The foam was cut into thin slice (as displayed in Fig. S1 (left)) to prepare carbon-silica composite slice. Afterwards, the obtained thin slice was put into boiling $2 \mathrm{~mol} / \mathrm{L} \mathrm{NaOH}$ solution for $2 \mathrm{~h}$ to remove the silica to obtain the hierarchical porous carbon slice (as showed in Fig. S1 (right)).

\subsection{Fabrication of $\mathrm{TiO}_{2}$ coated porous carbon-sulfur composite electrodes}

The as-prepared carbon slice and sulfur were mixed together in a weight ratio of 3:7 and heated to $160{ }^{\circ} \mathrm{C}$ in a sealed stainless steel autoclave for $24 \mathrm{~h}$ to facilitate sulfur diffusion into the carbon host. Then, the composite was heated at $200{ }^{\circ} \mathrm{C}$ and kept for 10 minutes under flowing argon gas $\left(50 \mathrm{~cm}^{3} \mathrm{~s}^{-1}\right)$ to vaporize the sulfur deposited on the outside surface of the composite (with the sample at this stage denoted as C-S). After that, titanium diisopropoxide bis(acetylacetonate) was used as the titanium precursor to coat a $\mathrm{TiO}_{2}$ layer on the surface of the C-S composite slice according to a previous report ${ }^{25}$ to obtain C-S- $\mathrm{TiO}_{2}$ slice (denoted as C-S- $\left.\mathrm{TiO}_{2}\right)$.

\subsection{Characterization}

The crystal phases of the resulting materials were analyzed by powder X-ray diffraction (XRD, MMA GBC, Australia). Thermogravimetric analysis (TGA) was carried out to determine the sulfur content with a TGA/differential scanning calorimetry (DSC) type instrument (METTLER TOLEDO, Switzerland) at a heating rate of $10{ }^{\circ} \mathrm{C} \mathrm{min}^{-1}$ from room temperature to $500{ }^{\circ} \mathrm{C}$ under argon atmosphere. The Brunauer-Emmett-Teller (BET) method was utilized to calculate the specific surface areas. The pore size distributions were derived from the adsorption branches of the isotherms based on the Barrett-Joyner-Halenda (BJH) model. The morphologies of the samples were investigated by field-emission scanning electron microscopy (FESEM; JEOL JSM-7500FA). Transmission electron microscope (TEM) images were collected on a JEOL 2011200 kV instrument. X-ray photoelectron spectroscopy (XPS) analysis was conducted on a VG Scientific ESCALAB 2201XL instrument using aluminum $\mathrm{K} \alpha \mathrm{X}$-ray radiation.

\subsection{Electrochemical measurement}

The C-S and C-S- $\mathrm{TiO}_{2}$ composite thin slices can be as a binder-free electrode for lithiumsulfur batteries that does not require any current collectors. Coin-type (CR2032) cells were assembled in an argon-filled glove box. The electrolyte used was $1 \mathrm{M}$ lithium bis(trifluoromethanesulfonyl)imide in a solvent mixture of 1,3-dioxolane (DOL): 
dimethoxyethane (DME) (1:1, v/v) containing $\mathrm{LiNO}_{3}$ (1 wt\%). The coin cells were galvanostatically charged-discharged between 1.5 and $3.0 \mathrm{~V}$ (vs. $\mathrm{Li} / \mathrm{Li}+$ ) by using a cell test instrument (CT2001A, LAND, China).

\section{Results and discussion}

A scanning electron microscope (SEM) image in Fig. 2 shows that the carbon slice is a 3D interconnecting network composed of prism-shaped struts with macropores about $300 \mu \mathrm{m}$ in diameter. Thermogravimetric (TG) curves of the C (inset in Fig. 2) displays a weight loss of $96 \mathrm{wt} \%$ from 400 to $650{ }^{\circ} \mathrm{C}$, indicating that the content of carbon is up to $96 \%$ and nearly all the silica has been removed from the carbon-silica composite.

As shown in Fig. 3(a), the X-ray diffraction (XRD) pattern of the carbon exhibits lowintensity and broad peaks, which reveal a typical amorphous structure. The pure elemental sulfur has various diffraction peaks, corresponding to an orthorhombic structure. As for the C-S and C-S- $\mathrm{TiO}_{2}$ composites, some diffraction peaks of the elemental S are visible, although the intensities become distinctly lower and some diffraction peaks even disappear, which suggests good dispersion of the $\mathrm{S}$ within the mesoporous carbon hosts [33]. The sulfur content in the C-S and C-S- $\mathrm{TiO}_{2}$ composites was determined by thermogravimetric analysis (TGA) conducted under argon atmosphere (as shown in Fig. 3(b)). The amount of sulfur in the C-S and C-S- $\mathrm{TiO}_{2}$ composites is $60 \mathrm{wt} \%$ and $53 \mathrm{wt} \%$, respectively.

The nitrogen adsorption-desorption isotherms of the $\mathrm{C}, \mathrm{C}-\mathrm{S}$, and C-S-TiO${ }_{2}$ composites are shown in Fig. 4(a) to confirm the pore structures. The isotherms of $\mathrm{C}$ and the C-S composite are type IV isotherms with hysteresis at relative pressure above 0.4 , which is characteristic of mesopores. Note that the insertion of sulfur leads to a significant decrease in the pore volume (from 1.26 to $0.33 \mathrm{~cm}^{3} / \mathrm{g}$ ) and Brunauer-Emmett-Teller (BET) surface area (1564 to $487 \mathrm{~m}^{2} / \mathrm{g}$ for C and C-S composite, respectively). Meanwhile, the pore size (Fig. 4(b)) also shows a strong decrease from $7 \mathrm{~nm}$ to $4.5 \mathrm{~nm}$, suggesting that a large portion of the pores are filled with sulfur. The C-S- $\mathrm{TiO}_{2}$ sample, however, does not exhibit a typical isotherm, indicating that the $\mathrm{TiO}_{2}$ layer almost completely covers the surface of the C-S composite.

Well-developed ordered mesostructure can be observed for the $\mathrm{C}$ sample, and the pore size estimated from the transmission electron microscope (TEM) image (Fig. 5(a)) is less than 8 $\mathrm{nm}$, in good accordance with the value from the $\mathrm{N}_{2}$ sorption isotherms. Moreover, compared to the $\mathrm{C}$, the contrast and the pore size of the C-S composite are obviously decreased, and no significant amount of bulk sulfur on the external surface is detected (Fig. 5(b)). This indicates 
that sulfur is homogeneously embedded in the mesopores of the sample due to the intense capillary forces. As for the C-S- $\mathrm{TiO}_{2}$ composite, the mesopores are not as clear as those in the $\mathrm{C}$ and the C-S composite due to the $\mathrm{TiO}_{2}$ coating on the surface of the C-S composite, resulting in a nearly complete lack of differentiation of the mesoporous composite (Fig. 5(c)). The scanning TEM (STEM) (Fig. 5(d)) and corresponding elemental mapping images of the C-S- $\mathrm{TiO}_{2}$ composite demonstrate that the $\mathrm{TiO}_{2}$ coating layer is evenly distributed on the surface of the C-S composite, which is also in good agreement with the results from the $\mathrm{N}_{2}$ sorption isotherms.

X-ray photoelectron spectroscopy (XPS) was used to further confirm and characterize the $\mathrm{TiO}_{2}$ coating layer on the surface of the C-S composite electrode (as displayed in Fig. S2). Three peaks positioned at 288.3, 284.9, and $283.7 \mathrm{eV}$ are observed from the C1s spectrum, which could be attributed to the $\mathrm{C}=\mathrm{O}, \mathrm{C}-\mathrm{O}$, and $\mathrm{C}=\mathrm{C} / \mathrm{C}-\mathrm{C}$ groups $[34,35]$, respectively, indicating that $\mathrm{C}$ still retains some oxygen-containing groups from the carbonization process of the carbon precursor. The S 2p spectrum exhibits two peaks at 164.8 and $163.7 \mathrm{eV}$, corresponding to the resolved S 2 $\mathrm{p}_{1 / 2}$ and $\mathrm{S} 2 \mathrm{p}_{3 / 2}$ peaks. Additionally, two peaks at 460.8 and $454.8 \mathrm{eV}$ corresponding to $\mathrm{Ti} 2 \mathrm{p}_{1 / 2}$ and $\mathrm{Ti} 2 \mathrm{p}_{3 / 2}$ are shown in the $\mathrm{Ti} 2 \mathrm{p}$ spectrum, demonstrating the presence of $\mathrm{Ti}^{4+}$ [36]. As the penetration depth of XPS is about $10 \mathrm{~nm}$, it is likely that the possible elemental sulfur signal is from places where the $\mathrm{TiO}_{2}$ layer is thinner than $10 \mathrm{~nm}$. The XPS results together with the TEM images and $\mathrm{N}_{2}$ sorption isotherms results reveal that most of the surface area of the C-S composite is covered with a $\mathrm{TiO}_{2}$ layer less than $10 \mathrm{~nm}$ in thickness.

The cycling performance of the C-S and the $\mathrm{TiO}_{2}$ coated composite electrodes at current rates of $0.2 \mathrm{C}$ and $1 \mathrm{C}$ is shown in Fig. 6(a). The initial discharge capacity is up to 1168 and 1111 $\mathrm{mAh} / \mathrm{g}$ for the C-S composite cathode at the $0.2 \mathrm{C}$ and $1 \mathrm{C}$ rates, while the $\mathrm{TiO}_{2}$ coated electrode delivers a corresponding discharge capacity of 1128 and $1076 \mathrm{mAh} / \mathrm{g}$, respectively, which is slightly lower than for the C-S composite cathode due to the poor conductivity of the $\mathrm{TiO}_{2}$ layer. This can be seen from the electrochemical impedance spectra (EIS) of the C-S and $\mathrm{C}-\mathrm{S}-\mathrm{TiO}_{2}$ electrodes, as shown in Fig. S3. The resistance of the C-S- $\mathrm{TiO}_{2}$ electrode is much higher than that of the C-S electrode, resulting in lower initial discharge capacity. In contrast, it is obvious that the $\mathrm{TiO}_{2}$ coated sample shows superior cycling performance in the long run. In the beginning, the capacities of the two samples are almost the same, however, the gap become more and more significant, especially after 20 cycles, as shown in Fig. 6(a). The discharge capacity at the $120^{\text {th }}$ cycle can reach $608 \mathrm{mAh} / \mathrm{g}$ at $0.2 \mathrm{C}$ and $500 \mathrm{mAh} / \mathrm{g}$ at the $1 \mathrm{C}$ rate for the $\mathrm{TiO}_{2}$ coated electrode, while the C-S composite cathode only exhibits 
corresponding capacities of 450 and $370 \mathrm{mAh} / \mathrm{g}$, respectively. This means that the mesopores of $\mathrm{C}$ can trap the polysulfides for a short time, but only a real capping layer can confine the polysulfides in the carbon matrix over a long span of time. Another important aspect that contributes to the stable cycling performance is that the $\mathrm{TiO}_{2}$ layer can effectively integrate the individual components in the electrode into a whole system and enhance the strength of the entire electrode to withstand structural damage during cycling. It is noted that specific capacity of the electrode without any binders and metal substrate in our study could be comparable with that using binders and substrate in previous report [21, 23-25]. This suggests that the polysulfides are better trapped inside the carbon matrix due to the $\mathrm{TiO}_{2}$ layer that is coated on the surface of the C-S composite.

The rate capability of the C-S and the $\mathrm{TiO}_{2}$ coated composite electrodes at different current rates, ranging from $0.2 \mathrm{C}$ to $5 \mathrm{C}$, is shown in Fig. 6(b). Compared with the C-S electrode, after $\mathrm{TiO}_{2}$ coating, the rate performance is obviously improved, especially at high current rates. The discharge capacity at the second discharge cycle for the C-S- $\mathrm{TiO}_{2}$ composite cathode is $1142 \mathrm{mAh} / \mathrm{g}$ at the current rate of $0.2 \mathrm{C}$, which is slightly lower than that of the C$\mathrm{S}$ composite. Nevertheless, the discharge capacity for the $\mathrm{C}-\mathrm{S}-\mathrm{TiO}_{2}$ electrode remains as high as $889,770,714,677$, and $650 \mathrm{mAh} / \mathrm{g}$, as the current density is increased to $0.5,1,2,3$, and 5 $\mathrm{C}$, respectively, which is much higher than the performance of the C-S composite, as shown in Fig. 6(b). Fig. 6(c) and (d) display the discharge/charge voltage profiles of C-S and C-S$\mathrm{TiO}_{2}$ electrodes at various rates, in which two plateaus at around 2.0 and $2.3 \mathrm{~V}$ are observed in the discharge process, which are typical characteristics of sulfur-carbon cathodes. Compared with previous report [13,18,37], rate capabilities (in table 1) for $\mathrm{TiO}_{2}$ coated samples are higher. On the one hand, 3D porous hierarchical structure could support rapid electronic/ionic transport and improve electrochemical kinetics. On the other hand, a possible reason is that the $\mathrm{TiO}_{2}$ works as an effective coating that helps to maintain the integrity of the electrode during charge and discharge processes. Together with the 3D hierarchically ordered porous carbon, it provides a real barrier to effectively trap polysulfides and minimize the dissolution of the polysulfides, thus reducing the loss of active mass in the cathode, and enhancing the electrochemical performance.

\section{Conclusions}

In summary, we have fabricated a 3D hierarchically ordered porous carbon-sulfur composite cathode, $\mathrm{TiO}_{2}$ layer has been further introduced on the surface of C-S composite to help trap the dissolved polysulfides and enhance the strength of the entire electrode, which leads to notably improved performance for the lithium-sulfur battery, especially over long cycling and 
at high rates. Furthermore, the 3D hierarchically ordered porous carbon slice can be mass produced in a simple way at low cost and carbon sulfur composite thin slice could work as a binder-free cathode without any current collectors for lithium-sulfur batteries, which makes our S-based electrode highly promising for practical application in lithium-sulfur batteries.

\section{Acknowledgments}

Financial support provided by the Australian Research Council (ARC) through an ARC Discovery project (DP1094261) is gratefully acknowledged. Moreover, the authors would like to thank Dr Tania Silver for critical reading of the manuscript and valuable remarks.

Table 1. Rate performance of Lithium-sulfur cathodes with different nanostructures

\begin{tabular}{lccccccc}
\hline different nanostructures & $0.1 \mathrm{C}$ & $0.2 \mathrm{C}$ & $0.5 \mathrm{C}$ & $1 \mathrm{C}$ & $2 \mathrm{C}$ & $3 \mathrm{C}$ & $5 \mathrm{C}$ \\
\hline $\begin{array}{l}\mathrm{TiO}_{2} \text { coated 3D hierarchically } \\
\text { porous architecture [this study] }\end{array}$ & - & 1142 & 889 & 770 & 714 & 677 & 650 \\
$\begin{array}{l}\text { porous hollow carbon-sulfur } \\
\text { composites [13] }\end{array}$ & - & 1150 & 970 & 750 & 600 & 450 & 820 \\
$\begin{array}{l}\text { sulfur in double-shelled hollow } \\
\text { carbon spheres [18] }\end{array}$ & 1080 & 820 & 550 & 350 & - & - & - \\
$\begin{array}{l}\text { graphene-based sandwich-type } \\
\text { architecture [37] }\end{array}$ & - & 1146 & 856 & 743 & 502 & - & - \\
\end{tabular}

\section{References}

[1] Pang HD, Yang ZX, Lv J, Yan WH, Guo TL. Novel MnOx@Carbon hybrid nanowires with core/shell architecture as highly reversible anode materials for lithium ion batteries. Energy 2014; 69:392-8.

[2] Yang ZX, Meng Q, Guo ZP, Yu XB, Guo TL. Highly reversible lithium storage in uniform $\mathrm{Li}_{4} \mathrm{Ti}_{5} \mathrm{O}_{12} /$ carbon hybrid nanowebs as anode material for lithium-ion batteries. Energy 2013; 55:925-32.

[3] Bruce PG, Freunberger SA, Hardwick LJ, Tarascon JM. Li- $\mathrm{O}_{2}$ and $\mathrm{Li}-\mathrm{S}$ batteries with high energy storage. Nat Mater 2012;11(1):19-29.

[4] Zhang XW, Kong X, Li GJ, Li J. Thermodynamic assessment of active cooling/heat methods for lithium-ion batteries of electric vehicles in extreme conditions. Energy 2014;64:1092-101.

[5] Seng KH, Li L, Chen DP, Chen ZX, Wang XL, Liu HK, Guo ZP. The effects of FEC 
(fluoroethylene carbonate) electrolyte additive on the lithium storage properties of $\mathrm{NiO}$ (nickel oxide) nanocuboids. Energy 2013; 58:707-13.

[6] Cheon SE, Choi SS, Han JS, Choi YS, Jung BH, Lim HS. Capacity fading mechanisms on cycling a high-capacity secondary sulfur cathode. $\mathrm{J}$ Electrochem Soc 2004;151(12):A2067-73.

[7] Xiong R, Sun FC, He HW, Nguyen TD. A data-driven adaptive state of charge and power capability joint estimator of lithium-ion polymer battery used in electric vehicles. Energy 2013; 63:295-308.

[8] Shim J, Striebel KA, Cairns EJ. The lithium/sulfur rechargeable cell-Effects of electrode composition and solvent on cell performance. J Electrochem Soc 2002;149(10):A1321-5.

[9] Novak P, Muller K, Santhanam KSV, Haas O. Electrochemically active polymers for rechargeble batteries. Chem Rev 1997;97(1):207-81.

[10] Yuan LX, Yuan HP, Qiu XP, Chen LQ, Zhu WT. Improvement of cycle property of sulfur-coated multi-walled carbon nanotubes composite cathode for lithium/sulfur batteries. J Power Sources 2009;189(2):1141-6.

[11] Mikhaylik YV, Akridge JR. Polysulfide shuttle study in the Li/S battery system. J Electrochem Soc 2004;151(11):A1969-76.

[12] He G, Ji XL, Nazar L. High "C" rate Li-S cathodes: sulfur imbibed bimodal porous carbons. Energy Environ Sci 2011;4(8):2878-83.

[13] Jayaprakash N, Shen J, Moganty SS, Corona A, Archer LA. Porous Hollow Carbon@Sulfur Composites for High-Power Lithium-Sulfur Batteries. Angew Chem Int Ed 2011;50(26):5904-8.

[14] Ahn W, Kim KB, Jung KN, Shin KH, Jin CS. Synthesis and electrochemical properties of a sulfur-multi walled carbon nanotubes composite as a cathode material for lithium sulfur batteries. J Power Sources 2012;202:394-9.

[15] Ellis BL, Lee KT, Nazar LF. Positive Electrode Materials for Li-Ion and Li-Batteries. Chem Mater 2010;22(3):691-714.

[16] Zhang B, Qin X, Li GR, Gao XP. Enhancement of long stability of sulfur cathode by encapsulating sulfur into micropores of carbon spheres. Energy Environ Sci 2010;3(10):1531-7.

[17] Schuster J, He G, Mandlmeier B, Yim T, Lee KT, Bein T, Nazar LF. Spherical Ordered Mesoporous Carbon Nanoparticles with High Porosity for Lithium-Sulfur Batteries. Angew Chem Int Ed 2012;51(15):3591-5.

[18] Zhang CF, Wu HB, Yuan CZ, Guo ZP, Lou XW. Confining Sulfur in Double-Shelled 
Hollow Carbon Spheres for Lithium-Sulfur Batteries. Angew Chem Int Ed 2012;51(38):9592-5.

[19] Dorfler S, Hagen M, Althues H, Tubke J, Kaskel S, Hoffmann MJ. High capacity vertical aligned carbon nanotube/sulfur composite cathodes for lithium-sulfur batteries. Chem Commun 2012;48(34):4097-9.

[20] Guo JC, Xu YH, Wang CS. Sulfur-Impregnated Disordered Carbon Nanotubes Cathode for Lithium-Sulfur Batteries. Nano Lett 2011;11(10):4288-94.

[21] Li NW, Zheng MB, Lu HL, Hu ZB, Shen CF, Chang XF, Ji GB, Cao JM, Shi Y. Highrate lithium-sulfur batteries promoted by reduced graphene oxide coating. Chem Commun 2012;48(34):4106-8.

[22] Wang JZ, Lu L, Choucair M, Stride JA, Xu X, Liu HK. Sulfur-graphene composite for rechargeable lithium batteries. J Power Sources 2011;196(16):7030-4.

[23] Zhang L, Ji LW, Glans PA, Zhang YG, Zhu JF, Guo JH. Electronic structure and chemical bonding of a graphene oxide-sulfur nanocomposite for use in superior performance lithium-sulfur cells. Phys Chem Chem Phys 2012;14(39):13670-5.

[24] Ji LW, Rao M, Zheng HM, Zhang L, Li YC, Duan WH, Guo JH, Cairns EJ, Zhang YG. Grapehe oxide as a sulfur immobilizer in high performance lithium/sulfur cells. J Am Chem Soc 2011;133(46):18522-5.

[25] Xiao LF, Cao YL, Xiao J, Schwenzer B, Engelhard MH, Saraf LV, Nie ZM, Exarhos GJ, and Liu J. A soft approach to encapsulate sulfur: polyaniline nanotubes for lithium-sulfur batteries with long cycle life. Adv Mater 2012;24(9):1176-81.

[26]Wu F. Chen JZ, Chen RJ, Wu SX, Li L, Chen S, Zhao T. Sulfur/Polythiophene with a Core/Shell Structure: Synthesis and Electrochemical Properties of the Cathode for Rechargeable Lithium Batteries. J Phys Chem C 2011;115(13):6057-63.

[27] Yang Y, Yu GH, Cha JJ, Wu H, Vosgueritchian M, Yao Y, Bao ZN and Cui Y. Improving the performance of lithium-sulfur batteries by conductive polymer coating. ACS Nano 2011;5(11):9187-93.

[28] Wu F, Chen JZ, Li L, Zhao $\mathrm{T}$, and Chen RJ. Improvement of rate and cycle performanceby rapid polyaniline coating of a MWCNT/sulfur cathode. J Phys Chem C 2011;115(49):24411-7.

[29] Seh ZW, Li WY, Cha JJ, Zheng GY, Yang Y, Mcdowell MT, Hsu PC, Cui Y. Sulphur$\mathrm{TiO}_{2}$ yolk-shell nanoarchitecture with internal void space for long-cycle lithium-sulphur batteries. Nat Commun 2013;4:1331.

[30] Kim H, Lee JT, Lee DC, Magasinski A, Cho W, Yushin G. Plasma-enhanced atomic 
layer deposition of ultrathin oxide coating for stabilized lithium-sulfur batteries. Adv Energy Mater 2013;3(10):1308-15.

[31] Lee KT, Black R, Yim T, Ji XL, Nazar LF. Surface-initiated growth of thin oxide coatings for Li-sulfur battery cathodes, Adv Energy Mater 2012;2(12):1490-6.

[32] Xue CF, Tu B, Zhao DY. Evaporation-induced coating and self-assembly of ordered mesoporous carbon-silica composite monoliths with macroporous architecture on polyurethane foams. Adv Funct Mater 2008;18(24):3914-21.

[33] Lai C, Gao X, Zhang B, Yan T, Zhou Z. Synthesis and electrochemical performance of sulfur-highly porous carbon composites. J Phys Chem C 2009;113(11):4712-6.

[34] Stankovich S, Dikin DA, Piner RD, Kohlhaas KA, Kleinhammes A, Jia Y, Wu Y, Nguyen ST, Ruoff RS. Synthesis of graphene-based nanosheets via chemical reduction of exfoliated graphite oxide. Carbon 2007;45(7):1558-65.

[35] Ding B, Yuan CZ, Shen LF, Xu GY, Nie P, Lai QX, Zhang XG. Chemically tailoring the nanostructure of graphene nanosheet to confine sulfur for high-performance lithium-sulfur batteries. J Mater Chem A 2013;1(4)1096-101.

[36] Li JY, Ding B, Xu GY, Hou LR, Zhang XG, Yuan CZ. Enhanced cycling performance and electrochemical reversibility of a novel sulfur-impregnated mesoporous hollow $\mathrm{TiO}_{2}$ sphere cathode for advanced Li-S batteries. Nanoscale, 2013;5(13):5743-6.

[37] Chen RJ, Zhao T, Lu J, Li L, Chen JZ, Tan GQ, Ye YS, Amine K. Nano Lett 2013;13(10):4642-9. 
FIGURES
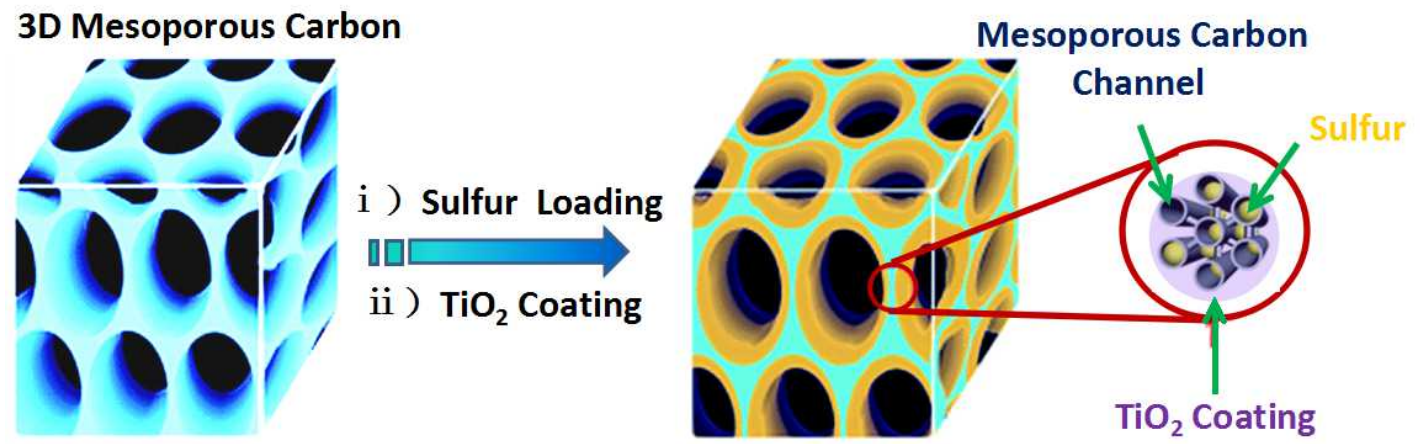

Fig.1 Pictorial representation of the structure of C-S-TiO ${ }_{2}$ composite. 


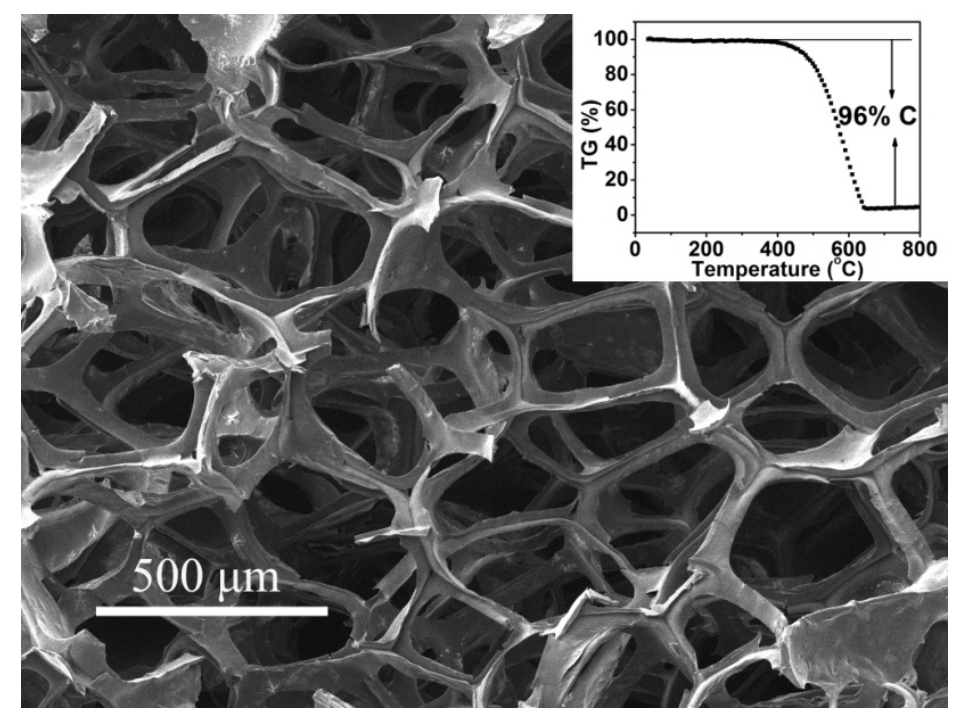

Fig. 2. SEM image of as-prepared carbon. Inset shows the TG curve of $C$ under air atmosphere to determine the content of carbon. 

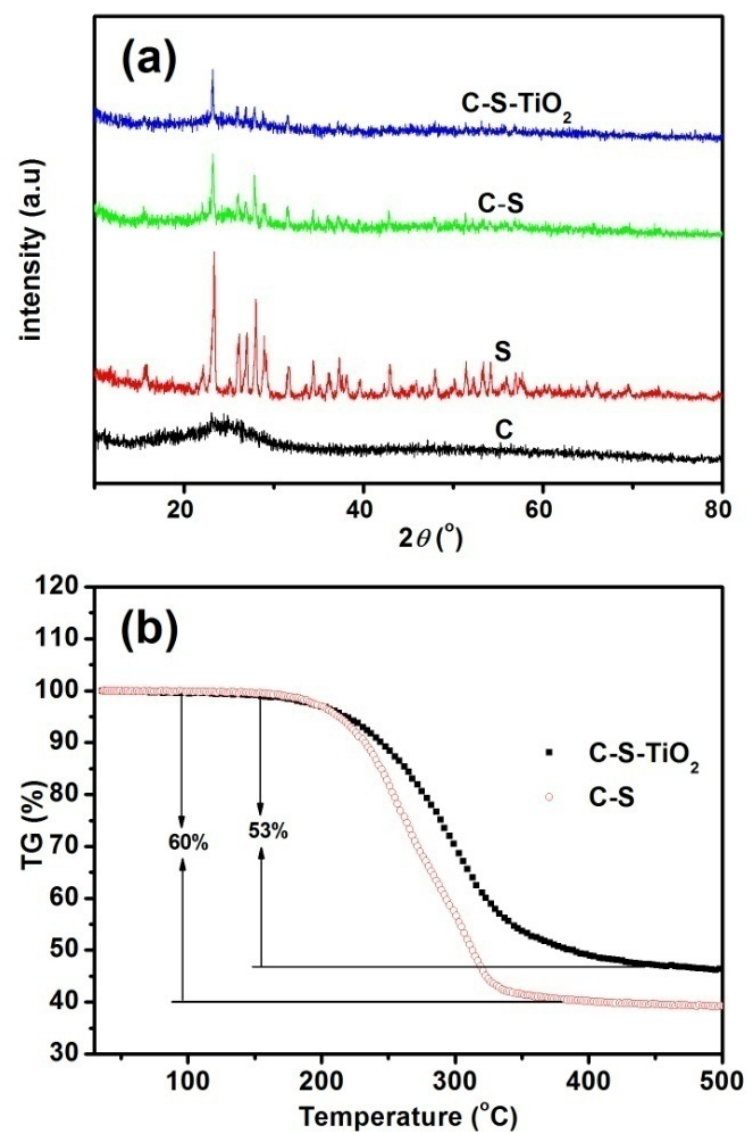

Fig. 3. (a) XRD patterns of C, S, C-S, and C-S-TiO ${ }_{2}$ composites, and (b) TG curves of C-S and $\mathrm{C}-\mathrm{S}-\mathrm{TiO}_{2}$ composites under argon atmosphere.
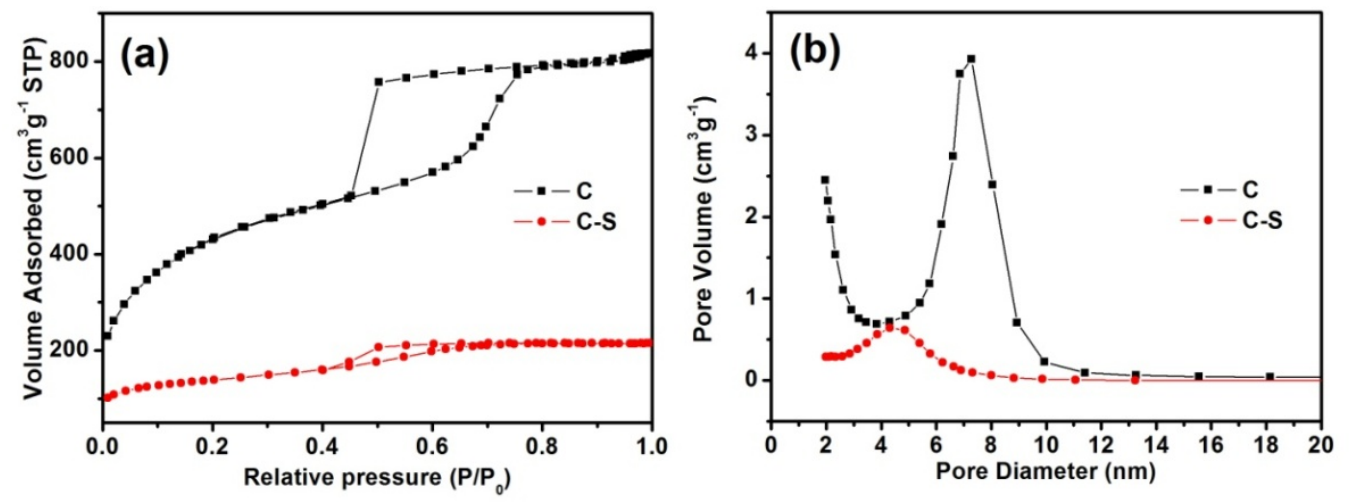

Fig. 4. (a) $\mathrm{N}_{2}$ sorption isotherms and (b) pore-size distributions of $\mathrm{C}$ and C-S composite. 


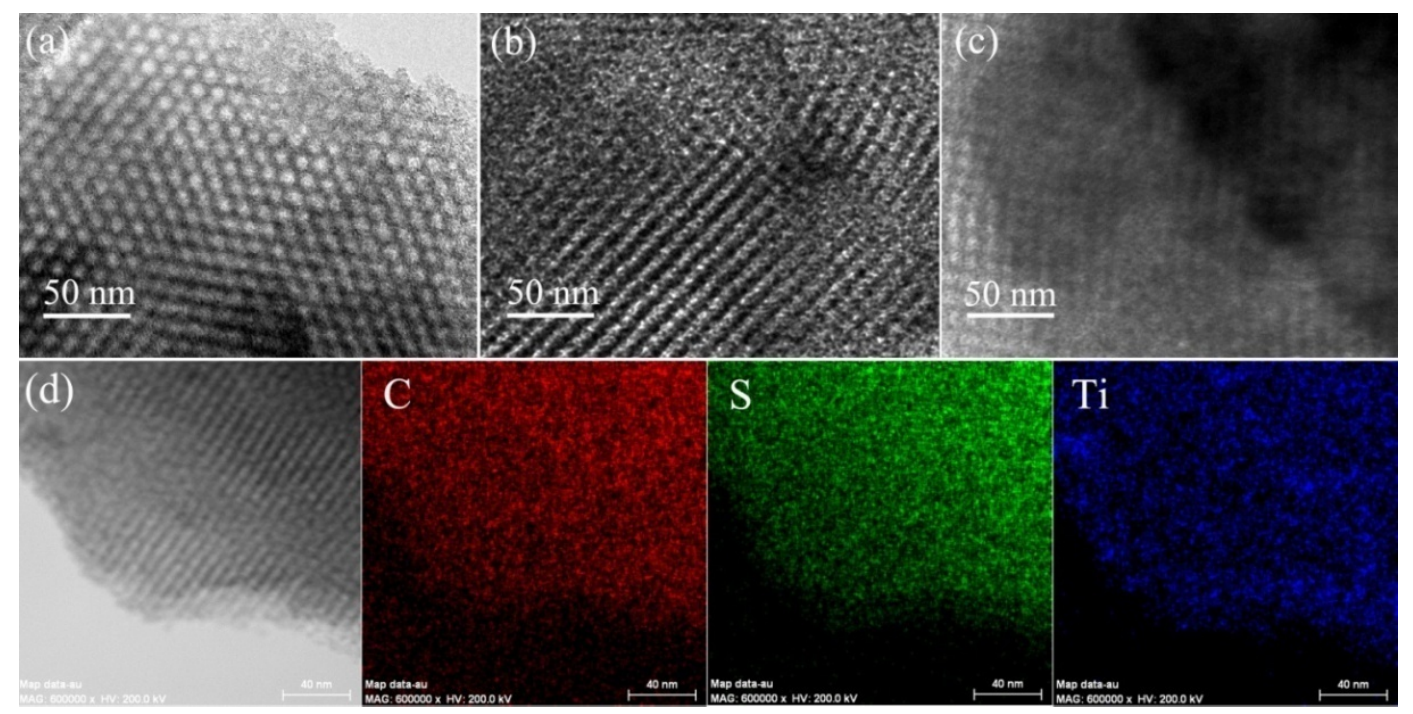

Fig. 5. TEM images of (a) C, (b) C-S composite, (c) C-S-TiO 2 composite, and (d) STEM image of $\mathrm{C}-\mathrm{S}-\mathrm{TiO}_{2}$ and corresponding elemental mapping images of $\mathrm{C}, \mathrm{S}$, and $\mathrm{Ti}$. 

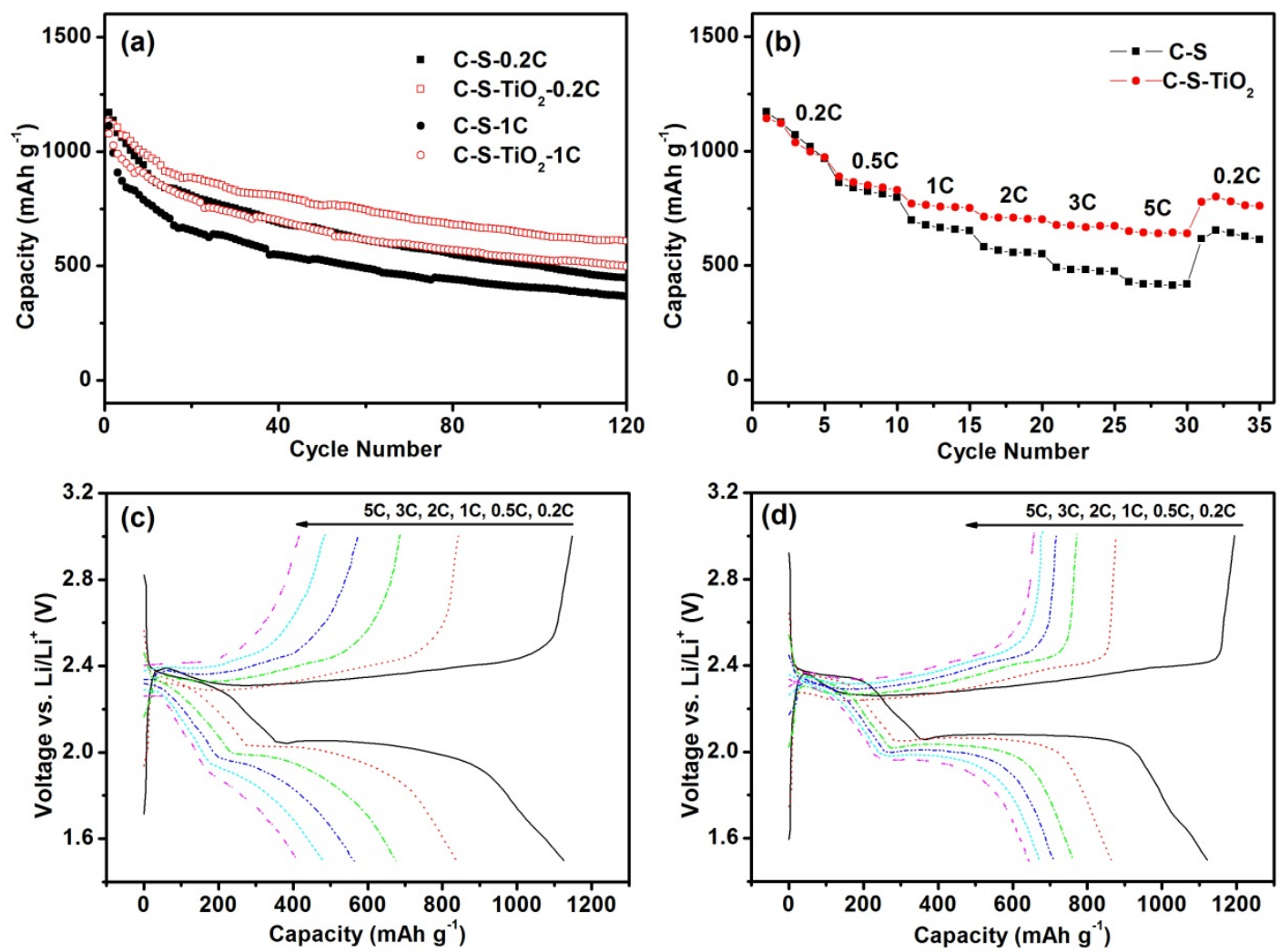

Fig. 6. (a) Cycling performances of C-S and C-S-TiO 2 electrodes at current densities of $0.2 \mathrm{C}$ and $1 \mathrm{C}$; (b) rate capabilities of $\mathrm{C}-\mathrm{S}$ and $\mathrm{C}-\mathrm{S}-\mathrm{TiO}_{2}$ electrodes; discharge/charge voltage profiles of (c) C-S and (d) $\mathrm{C}-\mathrm{S}-\mathrm{TiO}_{2}$ electrodes at various rates. 